\section{Use of Ödman-Ledin catheter and Seldinger wire with Crosby capsule}

\author{
P. FRIČ AND J. LEPŠíK From the Second Research \\ Unit of Gastroenterology, Charles University, \\ Prague, Czechoslovakia
}

Cox (1963) suggested radio-opaque polyvinylchloride tubing for easier localization of the Crosby capsule. We have found that the Ödman-Ledin red (no. 1) arterial catheter with a Seldinger guide wire ${ }^{1}$ is preferable for biopsies of the proximal jejunum.

One end of a $130 \mathrm{~cm}$. long catheter is rubbed down for several centimetres with fine emery paper until the capsule can be threaded on to it. A flange, large enough to fill the groove in the base of the capsule, is made at the end of the catheter by heating in a flame. Just before the capsule is swallowed the catheter is filled with normal saline and a $130 \mathrm{~cm}$. guide wire inserted up to the base of the capsule. The proximal end of the catheter with the protruding guide wire is clamped with a haemostat. The capsule is passed in the usual way (Crosby and Kugler, 1957) with fluoroscopic control to the proximal jejunum

${ }^{1}$ Manufactured by Kifa Co., Stockholm, Sweden.

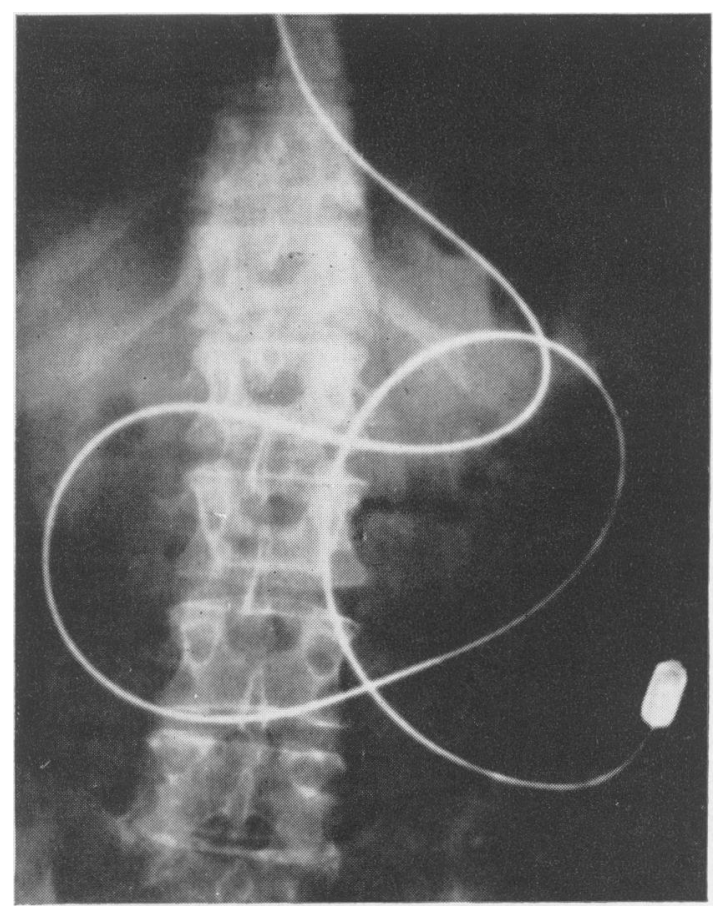

FIG. 1. Radiograph of the abdomen showing Crosby capsule with Ödman-Ledin catheter and Seldinger guide wire introduced into the proximal jejunum.

\section{Gastroenterological Society of Australia}

The annual meeting of the Gastroenterological Society of Australia was held at the Royal Prince Alfred Hospital, Sydney, on 3 May 1964. The President, Dr. S. J. M. Goulston, was in the chair.

After the business meeting a scientific session was held, at which the following papers were presented.

\section{EFFECT OF COLCHICINE ON SMALL INTESTINAL MUCOSA OF THE RAT}

KERRY GOULSTON and ALAN SKYRING Colchicine arrests cells undergoing mitosis at the metaphase. It has been claimed that the histopathology of the small intestine mucosa produced by repeated injections of sublethal doses of colchicine resembles that seen in idiopathic steatorrhoea. In this study it was found that the histopathology of the small intestinal mucosa did not resemble that of 'subtotal villous atrophy', in that there was atrophy and distortion of crypts as well as villi, with decreased mitoses. This was discussed in relation to the hypotheses of the pathogenesis of idiopathic steatorrhoea.

THREE UNUSUAL EXAMPLES OF INTESTINAL MALABSORPTION

W. B. HENNESSY and J. C. BIGGS In this paper three unusual examples of intestinal malabsorption were

Use of Ödman-Ledin catheter and Seldinger wire with Crosby capsule-continued

and the guide wire is then removed by gentle traction with the patient sitting. The patient then lies on the left side until the biopsy has been obtained, when the capsule is removed with the patient sitting with the cervical spine maximally extended.

The advantages of this method are 1: The catheter and guide wire may be readily directed into the pharyngeal orifice and to a certain extent passive introduction of the capsule may help it to be swallowed; 2 if the catheter is bitten it will still function, and the working life is much greater than that of a polyethylene tube; 3 radio-opacity is greater than with any other tube or instilled liquid (Fig. 1); 4 in most cases the upper jejunum is reached in 45 minutes.

Although the movement of bubbles cannot be seen along the catheter, the resistance experienced when injecting fluid or air into the catheter indicates that the knife has been released.

\section{REFERENCES}

Cox, A. G. (1963). Easier localization of the Crosby capsule in the alimentary tract. Gut, 4,413 .

Crosby, W. H., and Kugler, H. W. (1957). Intraluminal biopsy of the small intestine: the intestinal biopsy capsule. Amer. J. dig. Dis., 2, 236-241. 